\title{
The association between dietary phytochemical index with depression and quality of life in iranian adolescent girls
}

\author{
Abbas Ali Sangouni ${ }^{1,2}$, Azam Ahmadi Vasmehjani ${ }^{1,2}$, Majid Ghayour-Mobarhan ${ }^{3}$, Gordon A. Ferns ${ }^{4}$ and \\ Sayyed Saeid Khayyatzadeh ${ }^{1,2^{*}}$ (D)
}

\begin{abstract}
Background: There is increasing evidence that the dietary intake of phytochemicals is inversely associated with severity of depression and positively associated with quality of life (QoL). The present study investigated the relationship between dietary phytochemical index (DPI) with depression and QoL scores in Iranian adolescent girls.

Methods: A total of 733 adolescent girls from Mashhad and Sabzevar cities in northeastern Iran were entered into this cross-sectional study. Assessment of depression and QoL was performed utilizing the Beck Depression Inventory (BDI) and SF-12v2 questionnaire, respectively. Assessment of dietary intake was undertaken by a qualified dietitian, using a validated food-frequency questionnaire (FFQ) containing 168 food items. To explore the association between DPI with QoL and depression, logistic regression was used in crude and adjusted models.

Results: The participants in the fourth quartile of DPI compared with the first quartile had a $50 \%$ lower odds of depression (OR: 0.50; 95\% Cl: 0.30-0.84, $P=0.009$ ) This relation remained significant in all adjusted models. The adolescents in highest quartile of DPI compared with the first quartile had 38\% lower odds of poor QoL (OR: 0.62; 95\% Cl: $0.41-0.94, P=0.02$ ). This association remained significant in adjusted models I and II, but not after adjusting for all confounding variables (OR: 0.67; 95\% Cl: 0.43-1.02, $P=0.06$ ) (Model III).

Conclusions: DPI was inversely associated with risk of depression. The association between DPI score and QoL remained unclear. Further prospective and interventional studies are required.
\end{abstract}

Keywords: Depression, Quality of life, Phytochemical, Diet, Adolescents

\section{Introduction}

The prevalence of depression is increasing, and due to its socioeconomic costs has become a major challenge for public health globally $[1,2]$. The estimated prevalence of depression is between 11.1 and $14.6 \%$, and is higher during adolescence [3, 4]. Females are more likely to develop depression than males [4]. The estimated

\footnotetext{
* Correspondence: Khayyatzadeh@yahoo.com

'Department of Nutrition, School of Public Health, Shahid Sadoughi University of Medical Sciences, 8914715645 Yazd, Iran

${ }^{2}$ Nutrition and Food Security Research Center, Shahid Sadoughi University of Medical Sciences, Yazd, Iran

Full list of author information is available at the end of the article
}

prevalence of depression in Iranian children and adolescents is $43.5 \%$ [4]. It is a main cause of teenage suicide $[5,6]$. The symptoms of depression are depressed mood and anhedonia [7]. It has been confirmed that obesity, oxidative stress, and inflammation are contributors to the development of depression [8-11]. Quality of life (QoL), which is defined as "the perception of individuals about their position in life in the context of the culture and value systems which is related to their goals, expectations, standards and concerns", is negatively affected by depression [12-14].

(c) The Author(s). 2022 Open Access This article is licensed under a Creative Commons Attribution 4.0 International License, which permits use, sharing, adaptation, distribution and reproduction in any medium or format, as long as you give appropriate credit to the original author(s) and the source, provide a link to the Creative Commons licence, and indicate if changes were made. The images or other third party material in this article are included in the article's Creative Commons licence, unless indicated otherwise in a credit line to the material. If material is not included in the article's Creative Commons licence and your intended use is not permitted by statutory regulation or exceeds the permitted use, you will need to obtain permission directly from the copyright holder. To view a copy of this licence, visit http://creativecommons.org/licenses/by/4.0/ The Creative Commons Public Domain Dedication waiver (http://creativecommons.org/publicdomain/zero/1.0/) applies to the data made available in this article, unless otherwise stated in a credit line to the data. 
The investigations demonstrated the association of the quality of diet with depression $[15,16]$. Adherence to the healthy dietary patterns containing high amount of vegetables, fruits, legumes and whole grains can exert a therapeutic effect on mental disorders, in particular depression [16, 17]. Phytochemicals such as phenolic acids, carotenoids, terpenoids, organosulfur compounds, and phytosterols are the antioxidant compounds of vegetables, fruits, whole grains, nuts and legumes [18]. The experimental studies have indicated the antidepressant activity of phytochemicals [19-21]. In addition, phytochemicals have beneficial effects on determinants of depression such as abdominal obesity, oxidative stress and inflammation [22-25]. Dietary phytochemical index (DPI), which is a scoring tool, can estimate the level of phytochemicals intake from diet [26]. Only one study evaluated the association between DPI and depression among adults, and found an inverse relationship between DPI scores and risk of depression [27]. To our knowledge, the association between DPI scores and QoL has not been evaluated. Therefore, we designed a crosssectional study to investigate the association between scores of DPI with depression and QoL in adolescent females.

\section{Methods and materials}

\section{Study population}

Utilizing a random cluster sampling method, a total of 1026 adolescent girls (aged 12-18 years) were selected from several schools of Mashhad and Sabzevar cities in northeastern Iran. 38 subjects were excluded, and 988 subjects were included in this cross-sectional study. In addition, 255 subjects were excluded from our analysis due to under-reporting of energy intake or overreporting of energy intake, and 733 adolescent girls were included in our analysis (Fig. 1). The exclusion criteria were: a history of autoimmune diseases, metabolic bone disease, all types of cancer, cardiovascular disorders, diabetes mellitus, hepatic or renal failure, malabsorption, thyroid, parathyroid, adrenal diseases, anorexia or bulimia nervosa, parental dissatisfaction, taking antiinflammatory, anti-depressant, antidiabetic, or antiobesity medications, consuming vitamin $\mathrm{D}$ or calcium supplement, and hormone therapy within the last 6 months. Before the beginning of the study, the subjects completed written informed consent, and the study was approved by the ethical committee of Mashhad University of Medical Sciences, Mashhad, Iran under ethical code: 931,188 .

\section{Physical activity and anthropometric assessments}

Assessment of physical activity was performed utilizing a modifiable activity questionnaire (MAQ) [28]. Measuring anthropometric parameters such as height, weight, and waist circumference (WC) was performed based on the standard protocols. Calculating body mass index (BMI) was performed using the following formula: weight $(\mathrm{kg})$ divided by square of height $\left(\mathrm{m}^{2}\right)$.

\section{Dietary assessment}

Dietary intakes of participants were collected using a valid and reliable food frequency questionnaire (FFQ), contained 147 food items [29]. Frequency of food items

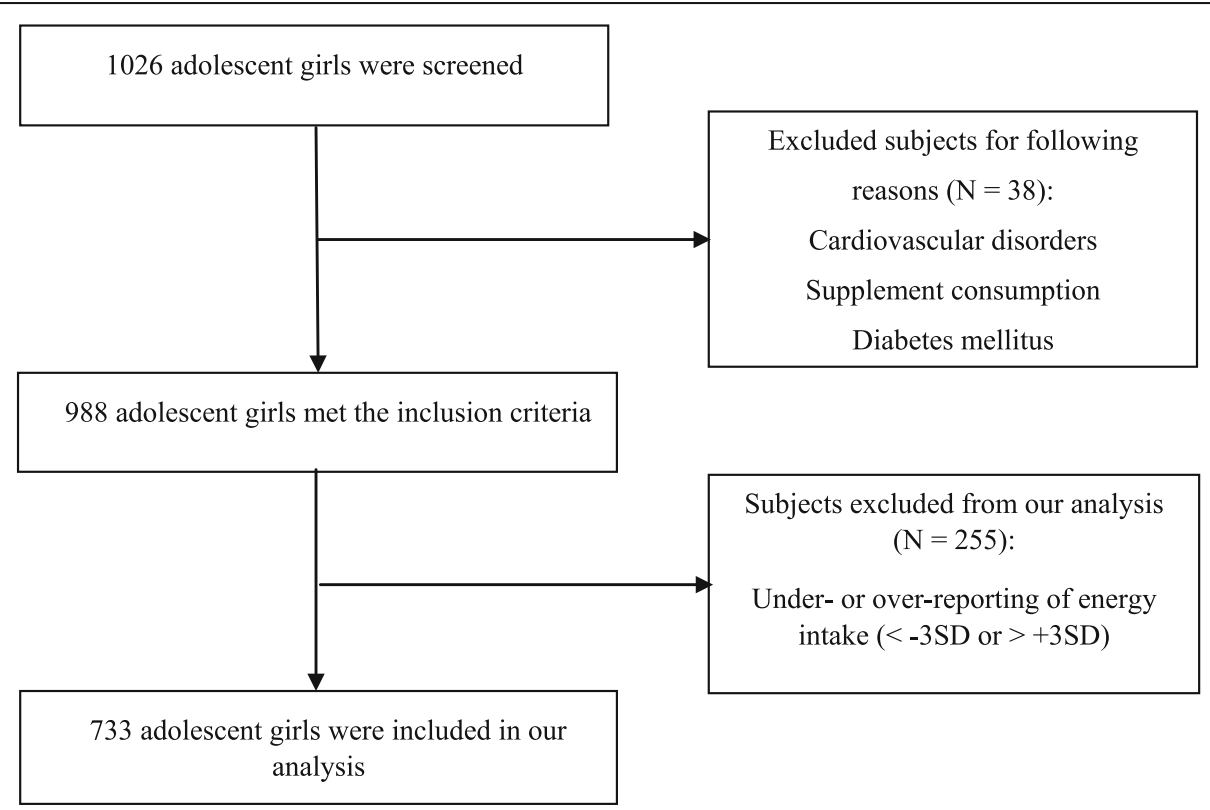

Fig. 1 Flowchart of the data collection process of study 
intake during the last year was evaluated by asking the participants about their daily, weekly, monthly and yearly intake. Converting portion sizes to grams was done by household measures. We used the Nutritionist IV software (version 7.0; N-Squared Computing, Salem, OR, USA), modified for Iranian foods, to analyze the dietary intakes [30]. Subjects under- or over-reporting of energy intake $(<-3$ standard deviation (SD) or $>+3 \mathrm{SD})$ were excluded from our analysis.

\section{Phytochemical index calculation}

The DPI score was computed using the following method, that was produced by McCarty [26]: DPI = (daily energy derived from phytochemical-rich foods $(\mathrm{kcal}) /$ total daily energy intake $(\mathrm{kcal})) \times 100$. The relationship between DPI and several diseases has been investigated [31-35]. The rich sources of phytochemical are fruits, vegetables, legumes, whole grains, nuts, soy products, seeds and olive oil. The content of phytochemicals in potatoes is not high, and we do not include the potatoes into the DPI formula. Natural fruit and vegetable juices as well as tomato sauces are the rich sources of phytochemicals, were entered in the fruit and vegetable groups.

\section{Assessment of depression}

Assessment of depression was performed using a Persian version of the 21-item beck depression inventory (BDI), that was validated by previous investigations $[36,37]$. The items are evaluating various symptoms of depression including feelings of guilt, feelings of hopelessness, sadness, crying, sleep disturbance, fear and loss of appetite over the past 2 weeks. The scores of BDI ranges between 0 (no depression) and 63 (severe depression), and BDI score more than 16 was considered as the cut-off value for the presence of depression $[37,38]$.

\section{Quality of life assessment}

We assessed the health-related QoL utilizing a validated SF-12v2 questionnaire, which is a short form of the SF36 questionnaire and improved version of SF-12v1 [39, 40]. The items of SF-12v2 questionnaire are evaluating the domains of health including physical functioning, role limitations because of physical problems, role limitations because of emotional problems, bodily pain, general health, vitality, social functioning, and mental health. The scores of QoL are from 0 to 100, and subjects with scores more than 43 (the median score of QoL is 43) were considered as subjects with high QoL.

\section{Biochemical assessments}

To measure serum concentrations of triglyceride (TG), total cholesterol (TC) and high density lipoproteincholesterol (HDL-c), blood samples were obtained while participants were in $14 \mathrm{~h}$ overnight fasting. To separate serum and plasma into two aliquots $(0.5 \mathrm{~mL})$, blood samples were immediately centrifuged (Hettich model D-78,532) for $10 \mathrm{~min}$ at room temperature. Then, serum samples were stored at $-80{ }^{\circ} \mathrm{C}$ at the reference laboratory in Mashhad University of medical science until analyses. TG, TC and HDL-c were measured by enzymatically method using Pars Azmoon, Karaj, Iran, and the BT3000 auto-analyzer machine (Biotechnica, Rome, Italy). Low density lipoprotein-cholesterol (LDL-c) was calculated using a validated formula (Friedewald equation) [41].

\section{Statistical analysis}

Utilizing a statistical package for social science (SPSS) software (Chicago, Illinois, USA) version 24, statistical analyses were performed. We categorized the subjects into the four groups based on their DPI scores. General characteristics as well as dietary intakes across quartiles of DPI score were expressed as means \pm SDs, and numbers (percentage) for continuous variables and categorical variables, respectively. We used one-way ANOVA for continuous variables and logistic regression analysis for categorical variables to calculate $\mathrm{p}$ for trend of each variables across the quartiles of DPI scores. The association between quartiles of DPI scores with depression and poor QoL was evaluated using a logistic regression analysis in the crude and adjusted models. One-way ANOVA for continuous variables (depression score and QoL score) and chi-square test for categorical variables (depression prevalence and poor QoL prevalence) was used to compare the differences between quartiles of DPI scores. In addition, logistic regression in crude and adjusted models was used to compare depression and poor QoL between quartiles of DPI scores. Age and energy intake were adjusted in Model (I) Additionally, BMI was adjusted in Model (II) In the model III, physical activity, age, energy intake, BMI, divorce of parents and death of parents were adjusted. $P<0.05$ was considered significant.

\section{Results \\ General characteristics study participants}

General characteristics of the study participants across categories of DPI are shown in Table 1 . The mean age of the participants was 14.5 years. The prevalence of depression and poor QoL were $24.8 \%$ and $49.7 \%$, respectively. Systolic blood pressure and diastolic blood pressure significantly increased across quartiles of DPI score $(\mathrm{P}$ trend $=0.002)$. HDL-c significantly decreased ( $\mathrm{P}$ trend $=0.027)$ across quartiles of DPI score, but BMI increased $(\mathrm{P}$ trend $=0.042)$. Other variables and general characteristics had no significant trend across quartiles of DPI. 
Table 1 General characteristics of study participants by quartiles of DPI

\begin{tabular}{|c|c|c|c|c|c|}
\hline Variables & $\begin{array}{l}\text { Q1 } \\
(N=183)\end{array}$ & $\begin{array}{l}\text { Q2 } \\
(N=183)\end{array}$ & $\begin{array}{l}\text { Q3 } \\
(N=184)\end{array}$ & $\begin{array}{l}\text { Q4 } \\
(N=183)\end{array}$ & P trend* \\
\hline Dietary phytochemical index (range) & $<15.2$ & $15.2-20.9$ & $20.9-29.9$ & $>29.9$ & \\
\hline Age (year) & $14.55 \pm 1.52$ & $14.47 \pm 1.48$ & $14.49 \pm 1.51$ & $14.53 \pm 1.63$ & 0.927 \\
\hline $\mathrm{BMI}\left(\mathrm{kg} / \mathrm{m}^{2}\right)$ & $20.76 \pm 3.98$ & $20.95 \pm 3.78$ & $21.66 \pm 4.77$ & $21.47 \pm 4.21$ & 0.042 \\
\hline Waist circumference $(\mathrm{cm})$ & $69.88 \pm 9.03$ & $70.04 \pm 8.35$ & $71.41 \pm 9.82$ & $70.67 \pm 9.10$ & 0.216 \\
\hline WHR & $0.76 \pm 0.05$ & $0.76 \pm 0.07$ & $0.77 \pm 0.05$ & $0.76 \pm 0.06$ & 0.874 \\
\hline Systolic blood pressure $(\mathrm{mm} / \mathrm{Hg})$ & $95.26 \pm 13.83^{b}$ & $95.39 \pm 13.69^{b}$ & $97.11 \pm 14.36$ & $99.56 \pm 13.95^{\mathrm{a}}$ & 0.002 \\
\hline Diastolic blood pressure (mm/Hg) & $61.71 \pm 14.23^{b}$ & $61.68 \pm 13.38^{b}$ & $62.41 \pm 13.27$ & $65.98 \pm 11.49^{\mathrm{a}}$ & 0.002 \\
\hline Metabolic equivalent for task (h/week) & $45.14 \pm 3.11$ & $45.18 \pm 3.13$ & $45.35 \pm 3.24$ & $45.82 \pm 4.17$ & 0.054 \\
\hline Triglyceride (mg/dL) & $84.06 \pm 38.81$ & $80.81 \pm 34.02$ & $85.89 \pm 39.08$ & $89.89 \pm 46.22$ & 0.657 \\
\hline Total cholesterol (mg/dL) & $162.21 \pm 27.88$ & $158.66 \pm 25.59$ & $165.13 \pm 28.32$ & $158.03 \pm 30.85$ & 0.946 \\
\hline $\mathrm{HDL}-\mathrm{c}(\mathrm{mg} / \mathrm{dL})$ & $46.69 \pm 8.92$ & $47.11 \pm 8.55$ & $48.31 \pm 8.88$ & $45.88 \pm 8.06$ & 0.027 \\
\hline LDL-c (mg/dL) & $101.28 \pm 25.63$ & $94.97 \pm 24.04$ & $103.91 \pm 26.37$ & $99.11 \pm 25.71$ & 0.386 \\
\hline Death of parent (\%) & $6(3.4 \%)$ & $8(4.5 \%)$ & $11(6.1 \%)$ & $4(2.2 \%)$ & 0.786 \\
\hline Divorce of parent (\%) & $10(5.6 \%)$ & $10(5.6 \%)$ & $11(6.1 \%)$ & $4(2.3 \%)$ & 0.193 \\
\hline
\end{tabular}

DPI: dietary phytochemical index. BMI: body mass index. WHR: waist-to-hip ratio. HDL-c: high-density lipoprotein-cholesterol. LDL-c: low-density lipoproteincholesterol. SD: standard deviation, values are means \pm SD, $n$ (\%): numbers (percentage). ${ }^{*}$ Obtained from one-way ANOVA and logistic regression analysis for continuous and categorical variables, respectively. ${ }^{a}$ : last quartile is considered as reference quartile, ${ }^{b}$ : Significant difference between quartile with reference quartile ( $P$ value $<0.05$ ).

\section{Dietary intake study participants}

Mean dietary intakes of participants across quartiles of DPI are provided in Table 2. Intake of protein and carbohydrate (per $1000 \mathrm{kcal}$ ) across quartiles of DPI significantly increased but fat intake decreased (P trend < 0.001). Vitamin B6, vitamin $C$, and folate intakes significantly increased across quartiles of DPI (P trend < $0.001)$, but thiamine intake decreased ( $\mathrm{P}$ trend $=0.005$ ). Iron and magnesium intakes significantly increased across quartiles of DPI (P trend $<0.001$ ). In addition, intake of saturated fatty acid ( $\mathrm{P}$ trend $<0.001$ ), MUFA ( $\mathrm{P}$ trend $<0.001$ ) and PUFA ( $\mathrm{P}$ trend $=0.005$ ) significantly decreased across quartiles of DPI. Intake of food groups including fruits, vegetables, legumes, nuts and whole grains (per $1000 \mathrm{kcal}$ ) significantly increased across quartiles of DPI score ( $\mathrm{P}$ trend $<0.001)$. Details are shown in Table 2.

\section{The association between DPI with depression and poor}

\section{QoL}

The prevalence of depression significantly decreased across quartiles of DPI score $(\mathrm{P}$ trend $=0.009)$. In addition, a significant reduction in depression score was found across quartiles of DPI score ( $\mathrm{P}$ trend $=0.002$ ). Adolescents in the highest quartile of DPI compared with the first quartile had a $50 \%$ lower odds of depression (OR: 0.50 ; $95 \% \mathrm{CI}$ : $0.30-0.84, P=0.009$ ). This relation remained significant after adjustment for age, energy intake, BMI, physical activity, divorce of parents and death of parents (OR: 0.48; 95\% CI: $0.28-0.83, P=$ 0.008). In all models, trend for odds of depression significantly reduced across DPI score (Table 3 ).

We found a significant reduction in prevalence of poor QoL across quartiles of DPI score ( $\mathrm{P}$ trend $=0.008$ ). However, no significant reduction in QoL score was observed across quartiles of DPI score $(P$ trend $=0.067$ ). The participants in the highest quartile of DPI compared with the lowest quartile had a $38 \%$ lower odds of poor QoL (OR: 0.62; 95\% CI: 0.41-0.94, $P=0.02$ ). This association was not significant after adjustment for age, energy intake, BMI, physical activity, divorce of parents and death of parents (OR: 0.67; 95\% CI: 0.43-1.02, $P=0.06$ ). In all models, trend for odds of poor QoL significantly reduced across DPI score (Table 3).

\section{Discussion}

Depression is an important precipitating cause of suicide ideation and suicide attempts in adolescents; therefore, management of depression is necessary $[5,6]$. Diet as a modifiable lifestyle factor has an important role in depression and subsequent QoL [42, 43]. Some studies revealed that adherence to the healthy, plant-based dietary patterns is inversely associated with risk of mental disorders $[17,44]$. Intake of plant foods that are rich sources of phytochemicals can increase the serum levels of phytochemicals [45]. For example, it has been confirmed that consuming whole grains, vegetables, whole fruit, legumes, nuts, seeds is directly associated with serum 
Table 2 Dietary intakes of study participants by quartiles of DPI

\begin{tabular}{|c|c|c|c|c|c|}
\hline Variables & $\begin{array}{l}\text { Q1 } \\
(N=183)\end{array}$ & $\begin{array}{l}\mathrm{Q} 2 \\
(N=183)\end{array}$ & $\begin{array}{l}Q 3 \\
(N=184)\end{array}$ & $\begin{array}{l}\mathrm{Q} 4 \\
(N=183)\end{array}$ & $P$ trend $^{* *}$ \\
\hline Energy $(\mathrm{kcal})^{*}$ & $2751.25 \pm 835.61$ & $2619.72 \pm 742.90$ & $2793.33 \pm 833.42$ & $2868.57 \pm 900.95$ & 0.932 \\
\hline Carbohydrate (gr/1000Kcal) & $134.62 \pm 21.85^{b}$ & $135.13 \pm 16.88^{b}$ & $135.69 \pm 16.73^{b}$ & $142.83 \pm 15.82^{\mathrm{a}}$ & $<0.001$ \\
\hline Protein (gr/1000Kcal) & $32.74 \pm 6.21^{\mathrm{b}}$ & $33.79 \pm 5.08^{b}$ & $34.32 \pm 4.56$ & $35.56 \pm 5.91^{\mathrm{a}}$ & $<0.001$ \\
\hline Fat (gr/1000Kcal) & $39.09 \pm 10.66^{b}$ & $38.15 \pm 7.93^{b}$ & $36.15 \pm 7.58^{b}$ & $34.98 \pm 7.05^{\mathrm{a}}$ & $<0.001$ \\
\hline Cholesterol (mg/100Kcal) & $86.20 \pm 55.66$ & $92.35 \pm 39.24$ & $91.64 \pm 38.68$ & $87.29 \pm 46.17$ & 0.865 \\
\hline Saturated fatty acid (gr/1000Kcal) & $11.51 \pm 3.82^{b}$ & $11.74 \pm 3.47^{b}$ & $11.28 \pm 3.06$ & $10.38 \pm 2.85^{\mathrm{a}}$ & $<0.001$ \\
\hline MUFA (gr/1000Kcal) & $13.08 \pm 4.36^{\mathrm{b}}$ & $12.13 \pm 3.15$ & $12.06 \pm 3.08$ & $11.23 \pm 2.82^{\mathrm{a}}$ & $<0.001$ \\
\hline PUFA (gr/1000Kcal) & $8.98 \pm 3.97^{b}$ & $8.20 \pm 2.78$ & $8.42 \pm 2.73$ & $7.91 \pm 2.92^{\mathrm{a}}$ & 0.004 \\
\hline Calcium (mg/1000Kcal) & $414.77 \pm 150.29$ & $438.53 \pm 134.59$ & $439.96 \pm 129.99$ & $412.06 \pm 120.88$ & 0.880 \\
\hline Iron (mg/1000Kcal) & $7.29 \pm 1.70^{b}$ & $7.12 \pm 1.34^{b}$ & $7.17 \pm 1.21^{\mathrm{b}}$ & $7.94 \pm 1.43^{\mathrm{a}}$ & $<0.001$ \\
\hline Magnesium (mg/1000Kcal) & $174.79 \pm 45.60^{b}$ & $171.18 \pm 35.40^{b}$ & $181.52 \pm 33.56^{\mathrm{b}}$ & $206.96 \pm 34.39^{a}$ & $<0.001$ \\
\hline Thiamine (mg/1000Kcal) & $0.89 \pm 0.21$ & $0.84 \pm 0.16$ & $0.80 \pm 0.15$ & $0.85 \pm 0.19$ & 0.005 \\
\hline Riboflavin (mg/1000Kcal) & $0.81 \pm 0.33$ & $0.83 \pm 0.19$ & $0.83 \pm 0.19$ & $0.81 \pm 0.19$ & 0.782 \\
\hline Niacin (mg/1000Kcal) & $9.30 \pm 2.24$ & $9.05 \pm 1.90$ & $8.65 \pm 1.82$ & $9.18 \pm 2.05$ & 0.242 \\
\hline Vitamin B6 (mg/1000Kcal) & $0.68 \pm 0.13^{b}$ & $0.70 \pm 0.11$ & $0.71 \pm 0.11$ & $0.74 \pm 0.14^{\mathrm{a}}$ & $<0.001$ \\
\hline Folate ( $\mu \mathrm{g} / 1000 \mathrm{Kcal})$ & $214.74 \pm 45.11^{b}$ & $228.88 \pm 44.22$ & $229.98 \pm 44.52$ & $239.69 \pm 58.66^{a}$ & $<0.001$ \\
\hline Vitamin B12 ( $\mu \mathrm{g} / 1000 \mathrm{Kcal})$ & $1.75 \pm 4.45$ & $1.58 \pm 0.71$ & $1.57 \pm 0.67$ & $1.44 \pm 0.77$ & 0.221 \\
\hline Vitamin C (mg/1000Kcal) & $24.89 \pm 11.32^{b}$ & $33.48 \pm 15.09^{b}$ & $41.33 \pm 19.83$ & $42.86 \pm 27.21^{\mathrm{a}}$ & $<0.001$ \\
\hline Vitamin A (IU/1000Kcal) & $209.25 \pm 438.47$ & $216.99 \pm 98.04$ & $231.29 \pm 100.13$ & $239.44 \pm 138.68$ & 0.188 \\
\hline Fruits (gr/1000 kcal) & $48.90 \pm 29.42^{\mathrm{b}}$ & $79.24 \pm 43.83^{b}$ & $105.45 \pm 70.05$ & $113.86 \pm 97.87^{\mathrm{a}}$ & $<0.001$ \\
\hline Vegetables (gr/1000 kcal) & $65.98 \pm 45.88^{b}$ & $83.30 \pm 48.62^{b}$ & $98.70 \pm 53.53$ & $110.56 \pm 80.14^{a}$ & $<0.001$ \\
\hline Legumes (gr/1000 kcal) & $15.59 \pm 9.77^{b}$ & $24.86 \pm 15.80^{b}$ & $29.59 \pm 16.08$ & $33.57 \pm 27.96^{\mathrm{a}}$ & $<0.001$ \\
\hline Nuts and seeds (gr/1000 kcal) & $2.00 \pm 1.88^{b}$ & $3.83 \pm 3.65^{b}$ & $6.72 \pm 6.43^{b}$ & $10.44 \pm 15.04^{\mathrm{a}}$ & $<0.001$ \\
\hline Whole grains (gr/1000 kcal) & $3.69 \pm 5.02^{b}$ & $8.91 \pm 10.70^{b}$ & $13.80 \pm 17.02^{\mathrm{b}}$ & $57.36 \pm 52.62^{a}$ & $<0.001$ \\
\hline
\end{tabular}

*Values are means \pm SDs and adjusted for energy intake, ${ }^{* *}$ Obtained from one-way ANOVA; DPI: dietary phytochemical index. MUFA: monounsaturated fatty acid. PUFA: polyunsaturated fatty acid. ${ }^{a}$ : last quartile is considered as reference quartile, ${ }^{\text {b}}$ : Significant difference between quartile with reference quartile ( $P$ value $<0.05)$.

phytochemicals [45]. In addition, serum phytochemicals are reliable variables of fruits and vegetables intake [46]. It has been reported that DPI, which is based on compounds with antioxidant properties, is directly associated with total carotenoid intake and is inversely associated with levels of oxidative stress [47]. This finding can confirm the accuracy of DPI in estimating phytochemicals intake. To our knowledge, the present cross-sectional study is the first study investigating the relationship between DPI with depression and QoL in adolescent females.

We demonstrated that higher DPI score is associated with decreased risk of depression. Only one cross-sectional study examined the association between DPI and mental disorders among adults [4], and demonstrated an inverse relationship between DPI scores with the risk of depressive symptoms, anxiety and psychological stress. Findings from a cohort study suggested that higher intake of flavonoids is associated with lower risk of incident depression [48].
In addition, the Mediterranean healthy eating, aging and lifestyle (MEAL) study reported an inverse relationship between intake of polyphenols and risk of depression [49]. Generally, phytochemicals by regulating dopaminergic brain pathways, enhancing serotonin and dopamine levels in the hippocampus and prefrontal cortex, and reducing monoamine oxidase (MAO) activity may improve depressive symptoms [19-21, 50].

On the other hand, a cross-sectional study revealed that higher intakes of fruits and vegetables are associated with levels of oxidative stress and inflammation as the main contributors of the pathogenesis of depression [51]. In addition, some studies have demonstrated that phytochemicals can improve oxidative stress [52, 53] and inflammation [54-56]. Phytochemicals can suppress fatty acid synthesis and gluconeogenesis, increase mitochondrial oxidation, reduce the levels of oxidant agents as well as free radicals, and attenuate the activity of inflammatory markers $[22-24,57,58]$. 
Table 3 The prevalence, score and OR (95\%Cl) of depression and poor QoL by quartiles of DPI

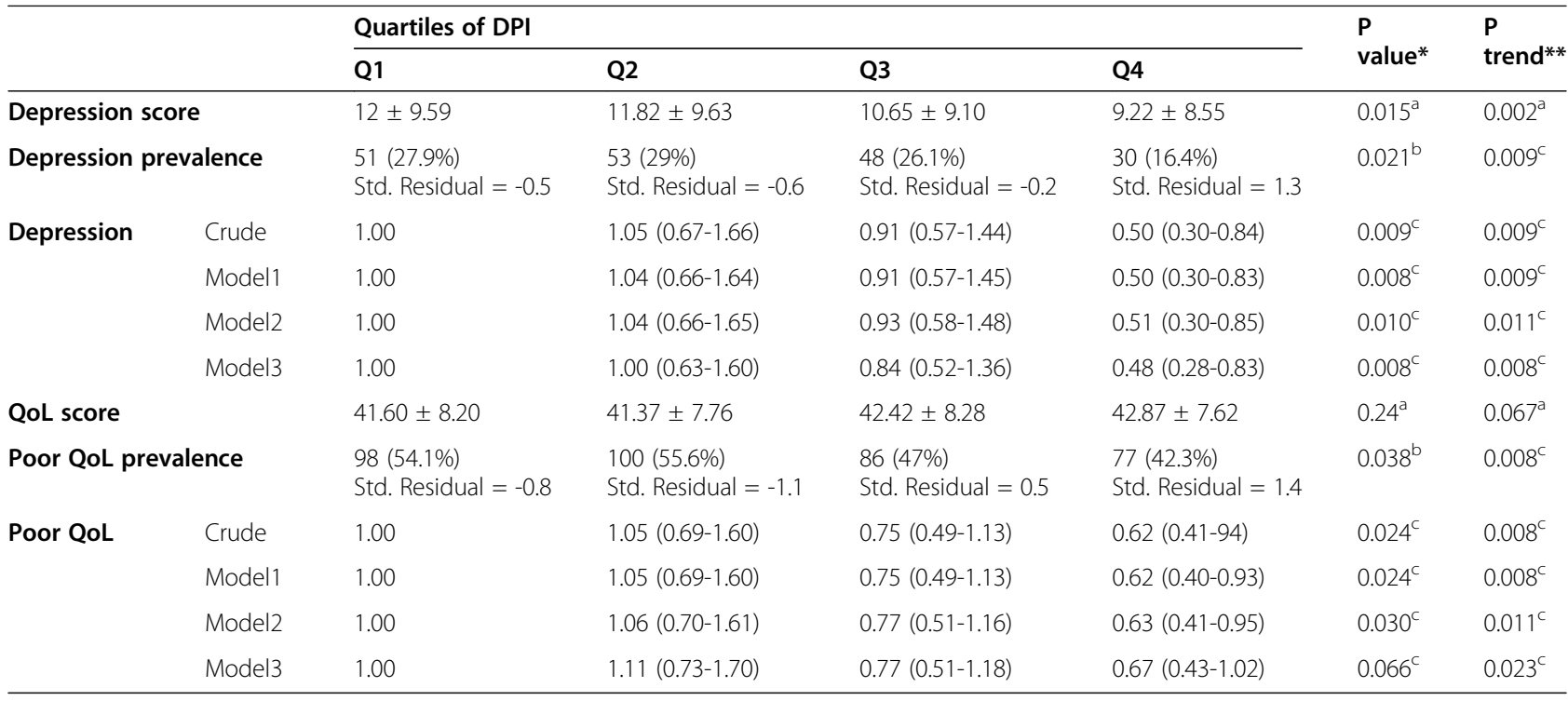

*Fourth quartile compared to first quartile.

**Trends across DPI quartiles.

a: Obtained from one-way ANOVA

b: Obtained from chi-square

c: Obtained from logistic regression

Model I: Adjusted for age and energy intake

Model II: Additionally, adjusted for BMI.

Model III: Additionally, adjusted for physical activity, divorce of parents and death of parents.

OR: odds ratio. CI: confidence interval. DPI: dietary phytochemical index. QoL: quality of life. BMI: body mass index.

There was no significant relationship between DPI score and QoL after adjusting for all confounding factors (Model III). However, we found a significant reduction trend in the odds of poor QoL across increasing quartile of DPI score. The relationship between DPI score with poor QoL remained unclear. Therefore, the findings in this field should be interpreted with caution. There was no investigation evaluating the association of phytochemicals with QoL. It has been shown that greater adherence to the Mediterranean diet as a plant-based diet, is associated with better QoL $[59,60]$. In addition, higher quality diets containing higher amounts of whole grains, fruits and vegetables as well as lower amounts refined foods and fast food are associated with better QoL [61-63]. Some food groups such as dairy products and seafood, which are found in these healthy dietary patterns, are not the sources of phytochemical, and we did not use these food groups in the calculation of DPI; therefore, specific investigations evaluating the association between phytochemicals and QoL are required.

The present study has some important strengths. This is the first study investigating the relationship between DPI scores depression and QoL among adolescents. In addition, we controlled the effects of several confounding factors. This study has some limitations. This is a cross-sectional study and we cannot show the causal link between DPI with depression and QoL. In addition, we did not include adolescent males in the study. Moreover, green and black tea (which are the rich sources of phytochemicals) were not considered for DPI calculation, because DPI formula is based on energy of phytochemicals sources and green and black tea did not contribute energy intake. Furthermore, we used FFQ to assess dietary intakes of participants, but dietary weighing method has higher accuracy compared to the FFQ.

In conclusion, we found that DPI score is negatively associated with risk of depression. However, according to inconsistent results, the associations between DPI score with poor QoL remained unclear. Further studies should be conducted, especially on both females and males. In addition, prospective and interventional investigations are needed to clarify casual relationships.

\section{Abbreviations}

BDI: beck depression inventory; BMI: body mass index; DPI: dietary phytochemical index; FFQ: food frequency questionnaire; HDL-c: high density lipoprotein-cholesterol; LDL-c: low density lipoprotein-cholesterol; MAO: monoamine oxidase; MAQ: modifiable activity questionnaire; MEAL: Mediterranean healthy eating, aging and lifestyle; OR: odds ratio; QoL: quality of life; SD: standard deviation; SPSS: statistical package for social science; TC: total cholesterol; TG: triglyceride; WC: waist circumference

\section{Acknowledgements}

We acknowledge the contribution of the participants and co-researchers.

\section{Authors' contributions}

S.Kh, M.Gh-M and G.F: designed the study. S.Kh: conducted the study; A.S and A.A: wrote the manuscript and involved in the analysis. S.Kh: critically revised the manuscript; S.Kh: supervised the study. The final version of the 
manuscript was approved by all authors. The author(s) read and approved the final manuscript.

\section{Funding}

Mashhad University of Medical Sciences (MUMS) supported this study.

\section{Availability of data and materials}

The data and materials of the current study is available from the corresponding author on reasonable request.

\section{Declarations}

\section{Ethics approval and consent to participate}

The ethical committee of Mashhad University of Medical Sciences in Mashhad approved the written informed consent (code number: 931188) The written informed consent was signed by all participants before the beginning study.

\section{Consent for publication}

Not applicable.

\section{Competing interests}

The authors have declared no competing interests.

\section{Author details}

'Department of Nutrition, School of Public Health, Shahid Sadoughi University of Medical Sciences, 8914715645 Yazd, Iran. ${ }^{2}$ Nutrition and Food Security Research Center, Shahid Sadoughi University of Medical Sciences, Yazd, Iran. ${ }^{3}$ Metabolic syndrome Research Center, Mashhad University of Medical Sciences, Mashhad, Iran. ${ }^{4}$ Brighton \& Sussex Medical School, Division of Medical Education, BN1 9PH Falmer, Brighton, Sussex, UK.

\section{Received: 1 October 2021 Accepted: 11 January 2022}

\section{Published online: 02 February 2022}

\section{References}

1. Collins PY, Patel V, Joestl SS, March D, Insel TR, Daar AS, et al. Grand challenges in global mental health. Nature. 2011;475(7354):27-30.

2. Kessler RC, Angermeyer M, Anthony JC, De Graaf R, Demyttenaere K, Gasque I, et al. Lifetime prevalence and age-of-onset distributions of mental disorders in the World Health Organization' s. World Psychiatry. 2007;6(3): 168-76.

3. Bromet E, Andrade LH, Hwang I, Sampson NA, Alonso J, de Girolamo G, et al. Cross-national epidemiology of DSM-IV major depressive episode. BMC Med. 2011;9(1):90

4. Sajjadi H, Mohaqeqi Kamal SH, Rafiey H, Vameghi M, Forouzan AS, Rezaei M. A systematic review of the prevalence and risk factors of depression among iranian adolescents. Glob J Health Sci. 2013:5(3):16-27.

5. Bilsen J. Suicide and Youth: Risk Factors. Front Psychiatry. 2018;9:540

6. Turecki G, Brent DA. Suicide and suicidal behaviour. Lancet. 2016;387(10024): 1227-39.

7. Uher R, Payne JL, Pavlova B, Perlis RH. Major depressive disorder in DSM-5: Implications for clinical practice and research of changes from DSM-IV. Depress Anxiety. 2014;31(6):459-71.

8. Shafiee M, Ahmadnezhad M, Tayefi M, Arekhi S, Vatanparast H, Esmaeili H, et al. Depression and anxiety symptoms are associated with prooxidantantioxidant balance: A population-based study. J Affect Disord. 2018;238: 491-8.

9. Shafiee M, Tayefi M, Hassanian SM, Ghaneifar Z, Parizadeh MR, Avan A, et al. Depression and anxiety symptoms are associated with white blood cell count and red cell distribution width: A sex-stratified analysis in a population-based study. Psychoneuroendocrinology. 2017:84:101-8.

10. Tayefi M, Shafiee M, Kazemi-Bajestani SMR, Esmaeili H, Darroudi S, Khakpour $S$, et al. Depression and anxiety both associate with serum level of hs-CRP: A gender-stratified analysis in a population-based study. Psychoneuroendocrinology. 2017:81:63-9.

11. Bergantin LB. The clinical link between depression and obesity: Role of Ca2+/cAMP signalling. Psychiatry Res. 2020:291:113167.

12. Teles F, Amorim de Albuquerque AL, Freitas Guedes Lins IK, Carvalho Medrado P. Falcão Pedrosa Costa A. Quality of life and depression in haemodialysis patients. Psychol Heal Med. 2018;23(9):1069-78.
13. Gao K, Su M, Sweet J, Calabrese JR. Correlation between depression/anxiety symptom severity and quality of life in patients with major depressive disorder or bipolar disorder. J Affect Disord. 2019;244:9-15.

14. Group: TW. The World Health Organization Quality of Life Assessment (WHOQOL): position paper from the World Health Organization. Soc Sci Med. 1995:41(10):1403-9.

15. Oddy WH, Allen KL, Trapp GSA, Ambrosini GL, Black $\sqcup$, Huang RC, et al. Dietary patterns, body mass index and inflammation: Pathways to depression and mental health problems in adolescents. Brain Behav Immun. 2018;69:428-39

16. Seon-Joo P, Myung-Sunny K, Hae-Jeung L. The association between dietary pattern and depression in middle-aged korean adults. Nutr Res Pract. 2019; 13(4):316-22.

17. Adjibade M, Assmann KE, Andreeva VA, Lemogne C, Hercberg S, Galan P, et al. Prospective association between adherence to the Mediterranean diet and risk of depressive symptoms in the French SU.VI.MAX cohort. Eur J Nutr 2018:57(3):1225-35.

18. Leitzmann C. Characteristics and Health Benefits of Phytochemicals. Forsch Komplementarmed. 2016;23(2):69-74.

19. Kulkarni SK, Bhutani MK, Bishnoi M. Antidepressant activity of curcumin: Involvement of serotonin and dopamine system. Psychopharmacology. 2008;201(3):435-42.

20. Yu Y, Wang R, Chen C, Du X, Ruan L, Sun J, et al. Antidepressant-like effect of trans-resveratrol in chronic stress model: Behavioral and neurochemical evidences. J Psychiatr Res. 2013;47(3):315-22.

21. Melo FHC, Moura BA, de Sousa DP, de Vasconcelos SMM, Macedo DS, Fonteles MM de. F, et al. Antidepressant-like effect of carvacrol (5-Isopropyl2-methylphenol) in mice: Involvement of dopaminergic system. Fundam Clin Pharmacol. 2011;25(3):362-7.

22. González-Castejón M, Rodriguez-Casado A. Dietary phytochemicals and thei potential effects on obesity: A review. Pharmacol Res. 2011;64(5):438-55.

23. Zhang YJ, Gan RY, Li S, Zhou Y, Li AN, Xu DP, et al. Antioxidant phytochemicals for the prevention and treatment of chronic diseases. Molecules. 2015:20(12):21138-56.

24. Zhu F, Du B, Xu B. Anti-inflammatory effects of phytochemicals from fruits, vegetables, and food legumes: A review. Crit Rev Food Sci Nutr. 2018:58(8): 1260-70.

25. Sangouni AA, Mohammad Hosseini Azar MR, Alizadeh M. Effect of garlic powder supplementation on hepatic steatosis, liver enzymes, and lipid profile in patients with non-alcoholic fatty liver disease: A double-blind randomized controlled clinical trial. Br J Nutr. 2020;124(4):450-6.

26. McCarty MF. Proposal for a dietary "phytochemical index.". Med Hypotheses. 2004:63(5):813-7.

27. Mofrad MD, Siassi F, Gilani B, Bellissimo N, Azadbakht L, Nutrition C, et al. Association of dietary phytochemical index and mental health in women: a cross-sectional study. Br J Nutr. 2019;121(9):1049-56.

28. Delshad M, Ghanbarian A, Ghaleh NR, Amirshekari G, Askari S, Azizi F. Reliability and validity of the modifiable activity questionnaire for an Iranian urban adolescent population. Int J Prev Med. 2015;6:3.

29. Asghari G, Rezazadeh A, Hosseini-Esfahani F, Mehrabi Y, Mirmiran P, Azizi F. Reliability, comparative validity and stability of dietary patterns derived from an FFQ in the Tehran Lipid and Glucose Study. Br J Nutr. 2012;108(6):1109-17.

30. Pehrsson PR, Haytowitz DB, Holden JM, Perry CR, Beckler DG. USDA's national food and nutrient analysis program: Food sampling. J Food Compos Anal. 2000;13(4):379-89.

31. Mofrad MD, Siassi F, Guilani B, Bellissimo N, Azadbakht L. Association of dietary phytochemical index and mental health in women: A cross-sectional study. Br J Nutr. 2019;121(9):1049-56.

32. Darabi Z, Sangouni AA, Darand M, Vasmehjani AA, Hosseinzadeh M. Dietary phytochemical index and attention-deficit/hyperactivity disorder in Iranian children: a case control study. Eur J Clin Nutr. 2021. https://doi.org/10.1038/ s41430-021-00952-z

33. Rigi S, Mousavi SM, Shakeri F, Keshteli AH, Benisi-Kohansal S, Saadatnia M, et al. Dietary phytochemical index in relation to risk of stroke: a case-control study. Nutr Neurosci. 2021;1-8. https://doi.org/10.1080/1028415X.2021.1954291.

34. Vasmehjani AA, Darabi Z, Nadjarzadeh A, Mirzaei M, Hosseinzadeh M. The relation between dietary phytochemical index and metabolic syndrome and its components in a large sample of Iranian adults: a population-based study. BMC Public Health. 2021;21(1):1-10.

35. Golzarand M, Bahadoran Z, Mirmiran P, Sadeghian-Sharif S, Azizi F. Dietary phytochemical index is inversely associated with the occurrence of 
hypertension in adults: A 3-year follow-up (the Tehran Lipid and Glucose Study). Eur J Clin Nutr. 2015;69(3):392-8.

36. Scogin F, Beutler L, Corbishley A, Hamblin D. Reliability and validity of the short form Beck Depression Inventory with older adults. J Clin Psychol. 1988; 44(6):853-7.

37. Ghassemzadeh H, Mojtabai R, Karamghadiri N, Ebrahimkhani N Psychometric properties of a Persian-language version of the Beck Depression Inventory-second edition: BDI-II-Persian. Depress Anxiety. 2005; 21(4):185-92.

38. Khayyatzadeh SS, Mehramiz M, Mirmousavi SJ, Mazidi M, Ziaee A, Kazemi-Bajestani SMR, et al. Adherence to a Dash-style diet in relation to depression and aggression in adolescent girls. Psychiatry Res. 2018; 259:104-9.

39. Cheak-Zamora NC, Wyrwich KW, McBride TD. Reliability and validity of the SF-12v2 in the medical expenditure panel survey. Qual Life Res. 2009;18(6): 727-35

40. Montazeri A, Vahdaninia M, Mousavi SJ, Asadi-Lari M, Omidvari S, Tavousi M. The 12-item medical outcomes study short form health survey version 2.0 (SF-12v2): A population-based validation study from Tehran, Iran. Health Qual Life Outcomes. 2011;9(1):12.

41. Atabi F, Mohammadi R. Clinical validation of eleven formulas for calculating LDL-C in Iran. Iran J Pathol. 2020;15(4):261-7.

42. Dowdy E, Furlong MJ, Sharkey JD. Using Surveillance of Mental Health to Increase Understanding of Youth Involvement in High-Risk Behaviors: A Value-Added Analysis. J Emot Behav Disord. 2013;21(1):33-44.

43. Michael SL, Lowry R, Merlo C, Cooper AC, Hyde ET, McKeon R. Physical activity, sedentary, and dietary behaviors associated with indicators of mental health and suicide risk. Prev Med Reports. 2020;19(May):101153.

44. O'Neil A, Quirk SE, Housden S, Brennan SL, Williams L, Pasco JA, et al. Relationship between diet and mental health in children and adolescents: A systematic review. Am J Public Health. 2014;104(10):e31-42.

45. Lipsky LM, Cheon K, Nansel TR, Albert PS. Candidate measures of whole plant food intake are related to biomarkers of nutrition and health in the US population (National Health and Nutrition Examination Survey 19992002). Nutr Res. 2012;32(4):251-9.

46. Van Kappel AL, Steghens J-P, Zeleniuch-Jacquotte A, Chajès V, Toniolo P, Riboli E. Serum carotenoids as biomarkers of fruit and vegetable consumption in the New York Women's Health Study. Public Health Nutr. 2001:4(3):829-35.

47. Vincent HK, Bourguignon CM, Taylor AG. Relationship of the dietary phytochemical index to weight gain, oxidative stress and inflammation in overweight young adults. J Hum Nutr Diet. 2010;23(1):20-9.

48. Chang SC, Cassidy A, Willett WC, Rimm EB, O'Reilly EJ, Okereke Ol. Dietary flavonoid intake and risk of incident depression in midlife and older women. Am J Clin Nutr. 2016;104(3):704-14.

49. Godos J, Castellano S, Ray S, Grosso G, Galvano F. Dietary polyphenol intake and depression: Results from the mediterranean healthy eating, lifestyle and aging (MEAL) study. Molecules. 2018;23(5):1-15.

50. Zotti M, Colaianna M, Morgese MG, Tucci P, Schiavone S, Avato P, et al. Carvacrol: From ancient flavoring to neuromodulatory agent. Molecules. 2013;18(6):6161-72.

51. Holt EM, Steffen LM, Moran A, Basu S, Steinberger J, Ross JA, et al. Fruit and Vegetable Consumption and Its Relation to Markers of Inflammation and Oxidative Stress in Adolescents. J Am Diet Assoc. 2009;109(3):414-21.

52. Sangouni AA, Mohammad Hosseini Azar MR, Alizadeh M. Effects of garlic powder supplementation on insulin resistance, oxidative stress, and body composition in patients with non-alcoholic fatty liver disease: A randomized controlled clinical trial. Complement Ther Med. 2020;51:102428. https://doi. org/10.1016/j.ctim.2020.102428.

53. Tabatabaie M, Abdollahi S, Salehi-Abargouei A, Clark CCT, Karimi-Nazari E, Fallahzadeh $\mathrm{H}_{\text {, et }}$ al. The effect of resveratrol supplementation on serum levels of asymmetric de-methyl-arginine and paraoxonase 1 activity in patients with type 2 diabetes: A randomized, double-blind controlled trial. Phyther Res. 2020;34(8):2023-31.

54. Hoseini A, Namazi G, Farrokhian A, Reiner Ž, Aghadavod E, Bahmani F, et al. The effects of resveratrol on metabolic status in patients with type 2 diabetes mellitus and coronary heart disease. Food Funct. 2019;10(9):6042-51.

55. Panahi Y, Hosseini MS, Khalili N, Naimi E, Simental-Mendía LE, Majeed M, et al. Effects of curcumin on serum cytokine concentrations in subjects with metabolic syndrome: A post-hoc analysis of a randomized controlled trial. Biomed Pharmacother. 2016;82:578-82.
56. Weisberg SP, Leibel R, Tortoriello DV. Dietary curcumin significantly improves obesity-associated inflammation and diabetes in mouse models of diabesity. Endocrinology. 2008;149(7):3549-58.

57. Pu P, Wang XA, Salim M, Zhu LH, Wang L, Chen kvo J, et al. Baicalein, a natural product, selectively activating AMPKa2 and ameliorates metabolic disorder in diet-induced mice. Mol Cell Endocrinol. 2012;362(1-2):128-38.

58. Wang L, Chen J, Xie H, Ju X, Liu RH. Phytochemical profiles and antioxidant activity of adlay varieties. J Agric Food Chem. 2013;61(21):5103-13.

59. Veronese N, Stubbs B, Noale M, Solmi M, Luchini C, Maggi S. Adherence to the Mediterranean diet is associated with better quality of life: Data from the Osteoarthritis Initiative. Am J Clin Nutr. 2016;104(5):1403-9.

60. Alcubierre N, Martinez-Alonso M, Valls J, Rubinat E, Traveset A, Hernández $\mathrm{M}$, et al. Relationship of the adherence to the Mediterranean diet with health-related quality of life and treatment satisfaction in patients with type 2 diabetes mellitus: A post-hoc analysis of a cross-sectional study. Health Qual Life Outcomes. 2016;14(1):4-9.

61. Sanchez-Aguadero N, Alonso-Dominguez R, Garcia-Ortiz L, Agudo-Conde C, Rodriguez-Martin C, de Cabo-Laso A, et al. Diet and physical activity in people with intermediate cardiovascular risk and their relationship with the health-related quality of life: Results from the MARK study. Health Qual Life Outcomes. 2016;14(1):1-10.

62. Rifai L, Pisano C, Hayden J, Sulo S, Silver MA. Impact of the Dash Diet on Endothelial Function, Exercise Capacity, and Quality of Life in Patients with Heart Failure. Baylor Univ Med Cent Proc. 2015;28(2):151-6.

63. Milte CM, Thorpe MG, Crawford D, Ball K, McNaughton SA. Associations of diet quality with health-related quality of life in older Australian men and women. Exp Gerontol. 2015;64:8-16.

\section{Publisher's Note}

Springer Nature remains neutral with regard to jurisdictional claims in published maps and institutional affiliations.

Ready to submit your research? Choose BMC and benefit from:

- fast, convenient online submission

- thorough peer review by experienced researchers in your field

- rapid publication on acceptance

- support for research data, including large and complex data types

- gold Open Access which fosters wider collaboration and increased citations

- maximum visibility for your research: over $100 \mathrm{M}$ website views per year

At $\mathrm{BMC}$, research is always in progress.

Learn more biomedcentral.com/submissions 